\title{
Association of -607 C/A Polymorphism of IL-18 Gene (rs 1946518) with Breast Cancer Risk in Zahedan, Southeast Iran
}

Taheri M.. ${ }^{1,2}$, Hashemi M.1,3, Eskandari-Nasab E. ${ }^{1}$, Fazaeli A. ${ }^{1}$, Arbabi F. ${ }^{4}$, Bahrani-Zeidabadi M. ${ }^{3}$, Bahari G. ${ }^{3}$

${ }^{1}$ Genetic of Non-Communicable Disease Research Center, Zahedan University of Medical Sciences, Zahedan, Iran;

2Department of Genetics, School of Medicine, Zahedan University of Medical Sciences, Zahedan, Iran;

${ }^{3}$ Department of Clinical Biochemistry, School of Medicine, Zahedan University of Medical Sciences, Zahedan, Iran;

${ }^{4}$ Department of Internal Medicine, School of Medicine, Zahedan University of Medical Sciences, Zahedan, Iran

Received January 18, 2012; Accepted June 25, 2012.

Key words: Breast cancer - IL-18 - Single nucleotide polymorphism

Abstract: It is known that interleukin-18 (IL-18) is a proinflammatory cytokine with dual effects on tumor development and progression. It can increase the immune defense against tumor cells. Polymorphisms in the IL-18 genes are known to influence both expression levels and may be associated with outcome of cancers. This study was aimed to find out the possible association of IL-18 polymorphism at position $-607 \mathrm{C} / \mathrm{A}$ (rs1946518) with breast cancer in a sample of Iranian population. We investigated IL-18 rs1946518 polymorphism on 72 breast cancer patients and 93 cancer free women. Genotyping was done using amplification refractory mutation system-PCR (ARMS-PCR). We found no significant differences between breast cancer patients and control subjects regarding IL-18 rs1946518 polymorphism $\left(\chi^{2}=1.78, p=0.411\right)$. In conclusion, our finding showed that IL-18 rs1946518 polymorphism was not associated with breast cancer in a sample of Iranian population.

This work was partially supported by research grant from Zahedan University of Medical Sciences.

Mailing Address: Prof. Mohammad Hashemi, PhD., Department of Clinical Biochemistry, School of Medicine, Zahedan University of Medical Sciences, Zahedan, Iran; e-mails: mhd.hashemi@gmail.com, hashemim@zaums.ac.ir 


\section{Introduction}

Breast cancer is the most common malignancy among women throughout the world and comprising $24.4 \%$ of all malignancies. It is a worldwide problem affecting more than 1 million women annually (Harirchi et al., 2011). According to reports of the Iranian Centre for the Prevention and Control of Disease; Ministry of Health and Medical Education; cancer is the third cause of death in Iran after coronary heart disease and accidents. Based on this report, breast cancer is the most prevalent cancer among Iranian women and accounts for $21.4 \%$ of all malignancies. Breast cancer mainly affects Iranian women about a decade earlier than western countries (Kolahdoozan et al., 2010).

Although the etiology of breast cancer is very complex, but some potential risk factors may contribute to the onset of breast cancer such as genetic, endocrine and environmental factors. In recent years, genetic polymorphisms are increasingly recognized as major contributors to breast cancer risk (De Vivo et al., 2003; Zhao et al., 2012).

IL-18, a member of the IL-1 family, can activate immune cells with or without IL-12 (Srivastava et al., 2010). IL-18 can regulate both innate and adaptive immune responses through its effects on natural killer (NK) cells, monocytes, dendritic cells, T cells, and B cells (Srivastava et al., 2010). It can increase the immune defense against tumor cells via activating and inducing the production of IFN- $\gamma$ and thus has a key role in Th1 response (Gunel et al., 2002). It has been shown that IL-18 has an important role in tumor progression. In various cancers, IL-18 expression and serum level have been shown to increase in the blood of metastatic patients compared to patients without metastasis and healthy controls (Park et al., 2007).

The IL-18 gene is located on chromosome 11 (11q22.2-22.3), and contains many polymorphism, especially in the promoter region (Smith and Humphries, 2009). Two polymorphisms in promoter region at positions $-137 \mathrm{G} / \mathrm{C}$ and $-607 \mathrm{C} / \mathrm{A}$ of IL-18 have been reported to affect their expression at transcription level (Giedraitis et al., 2001). To the best of our knowledge, the association of IL-18 gene polymorphisms with breast cancer is small and not fully recognized. The present study is aimed to determine the possible association between IL-18 $-607 \mathrm{C} / \mathrm{A}$ gene polymorphism and breast cancer in a sample of Iranian population.

\section{Material and Methods}

This case-control study was done on 72 patients with breast cancer (ages; $44.8 \pm$ 11.6 years) and 93 cancer free healthy women (ages; $37.6 \pm 15.2$ years). The project was approved by the local ethics committee of the Zahedan University of Medical Sciences. The diagnosis of cancer was confirmed by histopathological analysis. Blood samples were collected in Na-EDTA tubes from patients and healthy controls and stored at $-20{ }^{\circ} \mathrm{C}$ until DNA extraction. Genomic DNA extraction from blood samples was carried out as described previously (Hashemi et al., 2010). 
Table 1 - Primers used for polymorphism determination

\begin{tabular}{lcc}
\hline \multicolumn{1}{c}{ Primer } & Sequence $\left(5^{\prime} \rightarrow 3^{\prime}\right)$ & $\mathrm{T}_{\mathrm{m}}\left({ }^{\circ} \mathrm{C}\right)$ \\
\hline Forward outer primer & CCTACAATGTTACAACACTTAAAAT & 53 \\
Reverse outer primer & ATAAGCCCTAAATATATGTATCCTTA & 53 \\
Forward inner primer & GATACCATCATTAGAATTTTGTG & 53 \\
Reverse inner primer & GCAGAAAGTGTAAAAATTATCAA & 53 \\
\hline
\end{tabular}

Genotyping of IL-18 -607 C/A polymorphism was performed by using tetra-primer amplification refractory mutation system (T-ARMS) as described previously (Taheri et al., 2012). The primers used are shown in Table 1. Polymerase chain reaction (PCR) was performed using commercially available PCR premix (AccuPower PCR PreMix, BIONEER, Daejeon, South Korea) according to the manufacturer procedure. Into a 0.2-ml PCR tube containing the AccuPower PCR PreMix, $1 \mu$ template DNA $(\sim 100 \mathrm{ng} / \mu \mathrm{l}), 1 \mu \mathrm{l}$ of each primer $(10 \mu \mathrm{M})$ and $15 \mu \mathrm{l}$ DNase-free water were added. The PCR condition was as follows: initial denaturation at $95^{\circ} \mathrm{C}$ for 5 min followed by 30 cycles, consisting of denaturation at $95^{\circ} \mathrm{C}$ for $30 \mathrm{~s}$, annealing at $54^{\circ} \mathrm{C}$ for $20 \mathrm{~s}$, and extension at $72{ }^{\circ} \mathrm{C}$ for $30 \mathrm{~s}$ with a final extension at $72{ }^{\circ} \mathrm{C}$ for $10 \mathrm{~min}$. The PCR products were analyzed by electrophoresis on a $2 \%$ agarose gel containing $0.5 \mu \mathrm{g} / \mathrm{ml}$ ethidium bromide and visualized under ultraviolet light. Product sizes were: 208 bp for the $C$ allele, 278 bp for the $A$ allele and 440 bp for control band.

The statistical analysis was done using the SPSS 18.0 software. The associations between genotypes of IL-18 and breast cancer was estimated by computing the odds ratio $(\mathrm{OR})$ and $95 \%$ confidence intervals $(95 \% \mathrm{Cl})$ from logistic regression analyses.

\section{Results}

The distributions of allele and genotype frequencies of $-607 \mathrm{C} / \mathrm{A}$ polymorphism of IL-18 in patient and control groups are shown in Table 2. The results showed that the frequency of homozygous CC, heterozygous $\mathrm{CA}$, and homozygous $\mathrm{AA}$ in breast cancer patients were $40.3 \%, 44.4 \%$, and $15.3 \%$, respectively. The frequency of CA -607 polymorphism in healthy individuals was $43 \%$ for CC, $48.4 \%$ for CA, and $8.6 \%$ for $\mathrm{AA}$. There was no significant difference in $-607 \mathrm{C} / \mathrm{A}$ polymorphism of IL-18 among breast cancer patients and normal subjects $(p=0.411)$.

As shown in Table 2 in the patient group, $C$ allele frequency was $62.5 \%$ and the $\mathrm{A}$ allele frequency was $37.5 \%$, and in the control group the frequencies were $67.2 \%$ for $C$ allele and $32.8 \%$ for $A$ allele. The allele frequency was not significantly different between controls and patients ( $p>0.05)$. The IL-18 -607 C/A genotypes polymorphism in case and control groups was consistent with Hardy-Weinberg equilibrium. 
Table 2 - The genotypes and allele distribution of IL-18 polymorphism in case and control groups

\begin{tabular}{lcccccc}
\hline Polymorphism & $\begin{array}{c}\text { BC patients } \\
n(\%)\end{array}$ & $\begin{array}{c}\text { Normal } \\
n(\%)\end{array}$ & $\begin{array}{c}\text { OR } \\
(95 \% \mathrm{Cl})\end{array}$ & $\mathrm{P}$ & $\begin{array}{c}\text { aOR } \\
(95 \% \mathrm{Cl})\end{array}$ & $\mathrm{P}$ \\
\hline Genotypes & & & & 1.00 & \\
\hline $\mathrm{CC}$ & $29(40.3)$ & $40(43)$ & 1.00 & & & \\
\hline CA & $32(44.4)$ & $45(48.4)$ & $1.29(0.83-2.01)$ & 0.257 & $1.40(0.88-2.23)$ & 0.155 \\
\hline AA & $11(15.3)$ & $8(8.6)$ & $1.09(0.53-2.19)$ & 0.813 & $1.05(0.51-2.19)$ & 0.888 \\
Alleles & & & & & & \\
\hline C & $90(62.5)$ & $125(67.2)$ & & & & \\
\hline A & $54(37.5)$ & $61(32.8)$ & $0.09(0.66-1.22)$ & 0.532 & & \\
\hline
\end{tabular}

adjusted for age

\section{Discussion}

Breast cancer is one of the most common malignancies among women worldwide; etiology of breast cancer is extremely complex and appears to involve various genetic, endocrine and external environmental factors (Snousi et al., 2010). Genetic alterations, such as single nucleotide polymorphisms have also been reported to be one of major factor to breast cancer risk (Zhao et al., 2012).

In the present study we attempted to determine the impact of IL-18 $-607 \mathrm{C} / \mathrm{A}$ polymorphism on the susceptibility of breast cancer in our population. We found no association between IL-18 -607 C/A polymorphism and susceptibility to breast cancer.

It has been reported that IL-18 levels may be used as a serum marker for monitoring the clinical course of patients with hematologic malignancies and gastric carcinoma. Gunel et al. (2002) have shown that serum levels of IL-18 were significantly higher in the metastatic patients than the nonmetastatic patients. They concluded that IL-18 levels can be valuable markers in monitoring metastatic breast carcinoma patients (Gunel et al., 2002). In addition to its confirmed role in breast cancer metastasis, IL-18 was shown to contribute to doxorubicin resistance. Because of its dual roles in both drug resistance and tumor metastasis, IL-18 may denote a useful drug target for breast cancer therapy (Yao et al., 2011). IL-18, a novel immunoregulatory cytokine, in synergy with IL-12, by up regulating of IFN- $\gamma$ has a key role in Th1 response. It has dual effect on cancer; ex part it has anti-tumor activities that are mediated by increasing of NK cell activity and induction of apoptosis in tumor cells (Srabovic et al., 2011). Besides, IL-18 has also been found to promote tumor progression (Park et al., 2007). Increased levels of IL-18 have been detected in various cancers. Besides, elevated IL-18 expression has been associated with tumor growth and metastasis in breast cancer (Gunel et al., 2002; Srabovic et al., 2011). 
It is being thought that two SNPs in the promoter region of the IL-18 gene regulated the expression of gene at the transcriptional level and changed the production level of IL-18 (Giedraitis et al., 2001).

Many studies have shown the role of this polymorphism as a risk factor for susceptibility to cancer. Nikiteas et al. (2007) in a study on patients with colorectal cancer (CRC) found that IL-18 polymorphism at position $-607 \mathrm{C} / \mathrm{A}$ is a risk factor. Their results revealed that $A C$ heterozygotes seem to have an increased risk for CRC, while homozygotes for the high expression $C$ allele are more protected against this malignancy (Nikiteas et al., 2007), which is accordance to Farjadfar et al. (2009) findings. In contrast to this finding Vairaktaris et al. (2007) showed that IL-18 does not seem to contribute to oncogenesis in the oral cavity. There are a few studies about the role of IL-18 in breast cancer. In accordance to our finding, Khalili-Azad et al. (2009) demonstrated that there was no significant association between genotype frequencies at position $-607 \mathrm{C} / \mathrm{A}$ and breast cancer or its clinicopathological parameters.

In conclusion, our finding does not support an association between IL-18 -670 C/A and risk of breast cancer in our population. Larger studies with different ethnicity are required to validate our findings.

Acknowledgements:The authors thank to the patients and healthy subjects who willingly participated in this study.

\section{References}

De Vivo, I., Hankinson, S. E., Colditz, G. A., Hunter, D. J. (2003) A functional polymorphism in the progesterone receptor gene is associated with an increase in breast cancer risk. Cancer Res. 63, 5236-5238.

Farjadfar, A., Mojtahedi, Z., Ghayumi, M.A., Erfani, N., Haghshenas, M. R., Ghaderi, A. (2009) Interleukin-18 promoter polymorphism is associated with lung cancer: a case-control study. Acta Oncol. 48,

971-976.

Giedraitis, V., He, B., Huang,W. X., Hillert, J. (2001) Cloning and mutation analysis of the human IL-18 promoter: a possible role of polymorphisms in expression regulation. J. Neuroimmunol. 112, 146-152.

Gunel, N., Coskun, U., Sancak, B., Gunel, U., Hasdemir, O., Bozkurt, S. (2002) Clinical importance of serum interleukin-18 and nitric oxide activities in breast carcinoma patients. Cancer 95, 663-667.

Harirchi, I., Kolahdoozan, S., Karbakhsh, M., Chegini, N., Mohseni, S. M., Montazeri, A., Momtahen, A. J., Kashefi, A., Ebrahimi, M. (2011) Twenty years of breast cancer in Iran: downstaging without a formal screening program. Ann. Oncol. 22, 93-97.

Hashemi, M., Moazeni-Roodi, A. K., Fazaeli, A., Sandoughi, M., Bardestani, G. R., Kordi-Tamandani, D. M., Ghavami, S. (2010) Lack of association between paraoxonase-1 Q192R polymorphism and rheumatoid arthritis in southeast Iran. Genet. Mol. Res. 9, 333-339.

Khalili-Azad, T., Razmkhah, M., Ghiam, A. F., Doroudchi, M., Talei, A. R., Mojtahedi, Z., Ghaderi, A. (2009) Association of interleukin-18 gene promoter polymorphisms with breast cancer. Neoplasma 56, 22-25.

Kolahdoozan, S., Sadjadi, A., Radmard, A. R., Khademi, H. (2010) Five common cancers in Iran. Arch. Iran. Med. 13, 143-146.

Nikiteas, N., Yannopoulos, A., Chatzitheofylaktou, A., Tsigris, C. (2007) Heterozygosity for interleukin-18 $-607 \mathrm{~A} / \mathrm{C}$ polymorphism is associated with risk for colorectal cancer. Anticancer Res. 27, 3849-3853. 
Park, S., Cheon, S., Cho, D. (2007) The dual effects of interleukin-18 in tumor progression. Cell. Mol. Immunol. 4, 329-335.

Smith, A. J., Humphries, S. E. (2009) Cytokine and cytokine receptor gene polymorphisms and their functionality. Cytokine Growth Factor Rev. 20, 43-59.

Snoussi, K., Mahfoudh, W., Bouaouina, N., Fekih, M., Khairi, H., Helal, A. N., Chouchane, L. (2010) Combined effects of IL-8 and CXCR2 gene polymorphisms on breast cancer susceptibility and aggressiveness. BMC Cancer 10, 283.

Srabovic, N., Mujagic, Z., Mujanovic-Mustedanagic, J., Muminovic, Z., Cickusic, E. (2011) Interleukin 18 expression in the primary breast cancer tumour tissue. Med. Glas. Ljek. komore Zenicko-doboj. kantona 8 , 109-115.

Srivastava, S., Salim, N., Robertson, M. J. (2010) Interleukin-18: biology and role in the immunotherapy of cancer. Curr. Med. Chem. 17, 3353-3357.

Taheri, M., Hashemi-Shahri, S. M., Hamzehnejadi, M., Naderi, M., Moazeni-Roodi, A., Bahari, G., Hashemi, M. (2012) Lack of association between interleukin-18 -607 C/A gene polymorphism and pulmonary tuberculosis in Zahedan, southeast Iran. Prauge Med. Rep. 113, 16-22.

Vairaktaris, E., Serefoglou, Z. C., Yapijakis, C., Agapi, C., Vassiliou, S., Nkenke, E., Antonis, V., Sofia, S., Neukam, F.W., Patsouris, E. (2007) The interleukin-18 -607A/C polymorphism is not associated with risk for oral cancer. Anticancer Res. 27, 4011-4014.

Yao, L., Zhang, Y., Chen, K., Hu, X., Xu, L. X. (2011) Discovery of IL-18 as a novel secreted protein contributing to doxorubicin resistance by comparative secretome analysis of MCF-7 and MCF-7/Dox. PLoS One 6, e24684.

Zhao, E., Cui, D., Yuan, L., Lu,W. (2012) MDM2 SNP309 polymorphism and breast cancer risk: a meta-analysis. Mol. Biol. Rep. 39, 3471-3477.

Taheri M. et al. 